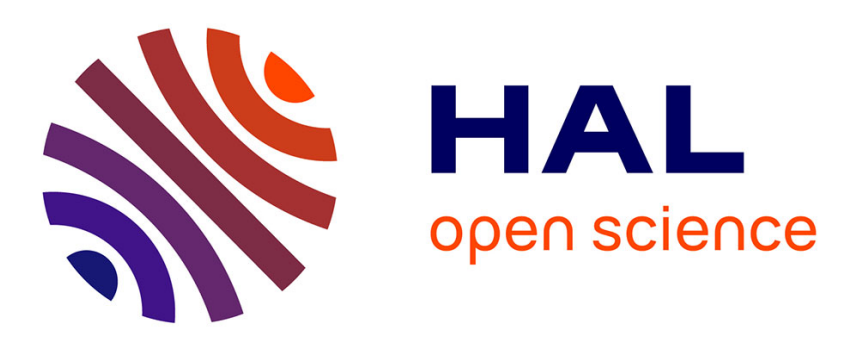

\title{
Insights in mechanisms of carbonaceous microparticles formation from black liquor hydrothermal conversion
}

Hélène Boucard, Elsa Weiss-Hortala, Fatou Gueye, Fabienne Espitalier, Radu Barna

\section{- To cite this version:}

Hélène Boucard, Elsa Weiss-Hortala, Fatou Gueye, Fabienne Espitalier, Radu Barna. Insights in mechanisms of carbonaceous microparticles formation from black liquor hydrothermal conversion. Journal of Supercritical Fluids, 2020, 161, pp.1-11/104817. 10.1016/j.supflu.2020.104817 . hal-02505499

\section{HAL Id: hal-02505499 \\ https://imt-mines-albi.hal.science/hal-02505499}

Submitted on 24 Mar 2020

HAL is a multi-disciplinary open access archive for the deposit and dissemination of scientific research documents, whether they are published or not. The documents may come from teaching and research institutions in France or abroad, or from public or private research centers.
L'archive ouverte pluridisciplinaire HAL, est destinée au dépôt et à la diffusion de documents scientifiques de niveau recherche, publiés ou non, émanant des établissements d'enseignement et de recherche français ou étrangers, des laboratoires publics ou privés. 


\title{
Insights in mechanisms of carbonaceous microparticles formation from black liquor hydrothermal conversion
}

\author{
Hélène Boucard, Elsa Weiss-Hortala, Fatou Gueye, Fabienne Espitalier, Radu Barna \\ Université de Toulouse, IMT Mines Albi, CNRS, RAPSODEE (UMR 5203), Campus Jarlard, CT Cedex 09, 81013, Albi, France
}

\section{H I G H L I G H T S}

- Degradation of black liquor results in formation of bio-oil, phenols, hydrochar.

- At short reaction time carbon microspheres are formed in the transition layer.

- At longer reaction time, microspheres are embedded in mesophase forming aggregates.

- In between, transition layer turns to a plastic mesophase in oily droplet.
G R A P H I C A L A B S T R A C T

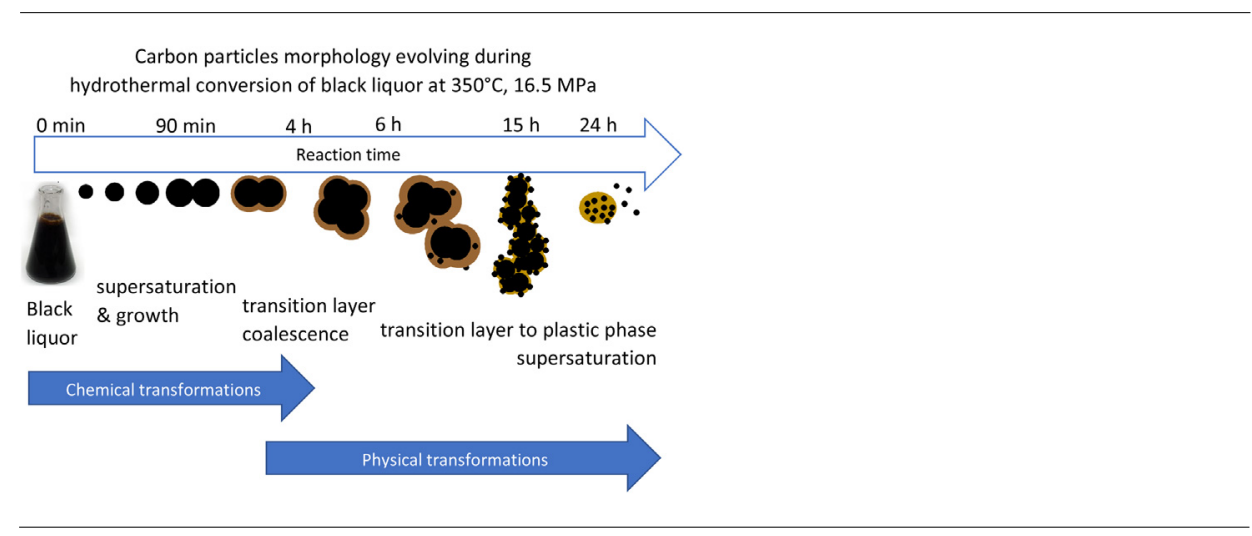

\section{A B S T R A C T}

The study addresses the formation of secondary hydrochar and the morphology of secondary microparticles from black liquor. The black liquor solution was hydrothermally converted at $350{ }^{\circ} \mathrm{C}$ and $16.5 \mathrm{MPa}$ in batch reactors running from $15 \mathrm{~min}$ to $24 \mathrm{~h}$ at different heating and cooling rates. Spherical carbon microparticles were obtained at a short reaction time ( $<90 \mathrm{~min})$ and then coalesced to form aggregates. At a very long reaction time $(24 \mathrm{~h}$ ), spherical carbon microparticles were obtained once again. The carbonaceous solid was enriched in carbon during the first $4 \mathrm{~h}$ of reaction. In parallel, the concentrations of total organic carbon and total phenols in the solution decreased drastically. The formation of solids was mainly due to chemical reactions occurring during the first $4 \mathrm{~h}$. Subsequent changes in the solids were mainly due to physical reorganization since the chemical compositions of solutions were almost stable.
Hydrothermal conversion

Secondary char formation

Microparticles generation

Black liquor

Hydrochar

Carbonaceous microparticles

\section{Introduction}

Hydrothermal processes $\left(\mathrm{T}>250{ }^{\circ} \mathrm{C}, \mathrm{P}>15 \mathrm{MPa}\right)$ use the properties of water, as reactant, solvent and/or catalyst to convert

E-mail addresses: boucard.h@gmail.com (H. Boucard), elsa.weiss@mines-albi.fr (E. Weiss-Hortala), f.salim99.9@hotmail.com (F. Gueye),

fabienne.espitalier@mines-albi.fr (F. Espitalier), radu.barna@mines-albi.fr (R. Barna). wet feedstock $[1,2]$. Indeed, water under supercritical conditions ( $\mathrm{T}>374{ }^{\circ} \mathrm{C}$; $\mathrm{P}>22.1 \mathrm{MPa}$ ) or close to supercritical conditions has reactive properties which combined give it interesting applications: oxidation [3], chemical reactions [1,4], waste treatment [5,6], biomass conversion [7-10], nanoparticles synthesis [11-15]. Depending on the operating conditions ( $T$, P, reaction time, concentration of feedstock...), and reagents (biomass, oxidant, catalyst...), targeted products are different: $\mathrm{H}_{2}$-rich gas is produced at high temperature during supercritical water gasification [7] while hydrothermal liquefaction and carbonization favor 
liquids and solid phases respectively [10,11,16-18]. Industrially, hydrothermal conversion raises many technical, technological and scientific challenges. Supercritical water gasification or hydrothermal liquefaction face to the solid generation, as a by-product, which limits the development of the continuous process. Alkali salts deposition and coke formation (or hydrochar) are the most important resulting in the clogging of reactors, corrosion of material and limitation of heat transfer efficiency [19].

Although researches have explored the hydrochar formation from HydroThermal Carbonization (HTC), few studies investigated the undesired hydrochar formation during hydrothermal liquefaction or supercritical water gasification. Hydrochar formation in HTC has common features with coalification [16,20]. Hydrochar, or coke, comes from primary and secondary chars. Primary char is basically obtained from decomposition of the original solid feedstock, while the secondary char comes from the reactions of dissolved organics into the liquid phase. The secondary char formation follows the sequential reactions of organics in liquid phase: hydrolysis, dehydration, fragmentation, decarboxylation, polymerization and condensation, polymer aromatization, and nucleation [18,19,21]. In other words, phenolic aromatics compounds and aldehydes, or basically aromatics and aliphatic hydrocarbons, react together through polymerization [18,22-25]. However, as the kinetics of polymerization increases, morphology of solid will evolved from "mesophase" spherules to fine spherules [26]. The mesophase is an intermediary state between a liquid and a solid but it has liquid properties.

Carbonization is due to chemical reactions between organics, and phase equilibrium as well that explains the morphology. HTC typically generates microparticles with interesting textural, morphological or physico-chemical properties [14-16,18,19,27]. Two theories of particle generation have been described in the literature. According to the theory of Brooks and Taylor, microparticles are generated from the solidification of mesophase microspheres [28]. Other authors completed the mesophase theory, considering a continuous media of a viscous plastic phase containing the carbonaceous microspheres [22,29-32]. Emergence of particles from the thin plastic layer is driven by a change in aromaticity degree of the carbonized precursor [29]. Inagaki followed Brooks and Taylor's theory and introduced the concept of BSU (Basic Structural Unit) to explain the formation of particles from the plastic layer [32]. BSU is the stable unit size of polymer (stable structure having the smallest number of monomers) forming carbonaceous particles. Particles growth by addition of BSU along the radius of microspheres [31], increasing the aromaticity of the particles. The size of particles is defined by the critical radius from nucleation law which allows a permanent existence of the particles. Particles with a smaller radius will disappear by sublimation or coalescence. To complete the "mesophase theory", Azami et al. [33] have shown that the mesophase formation follows the Arrhenius equation, and rearrangements into the mesophase result in bigger molecules.

From La Mer theory [34], solid particles are generated in the liquid phase from nuclei due to a local supersaturation in the mother phase. Compositions of nucleus and liquid phase being significantly different, their immiscibility leads to the formation of dispersed anisotropic droplets in the liquid phase. The transition layer between both phases forms a continuous media from solid to liquid phase. These particles are expected to growth or disappear, and the presence of lignin increases the homogeneity and the purity of microspheres [21].

In both theories, operating conditions such as temperature and reaction time extremely influence the solid particle generation. Fang et al. [35] have shown that particles precipitated from 250 ${ }^{\circ} \mathrm{C}$. After reaction, three phases were obtained: an oily orange film, and aqueous liquid phase and solid phase at the bottom of the cell.
Table 1

Composition of the raw black liquor from the paper company and from our measurements.

\begin{tabular}{ll}
\hline $\mathrm{pH}$ & 13.2 \\
\hline Dry matter & 23.0 wt. \% \\
Organic content & Composition in wt. \% of dry matter \\
Lignin content & 36.2 \\
Polysaccharides & 2.5 \\
Carboxylic acids* & 11.3 \\
Inorganic content & Composition in wt. \% of dry matter \\
Sodium & 15.4 \\
Potassium & 1.3 \\
Carbonates & 5.7 \\
Sulfur & 3.4 \\
Sulfide & 2.3 \\
Sulfate & 1.1 \\
Residual NaOH & 5.2 \\
\hline
\end{tabular}

carboxylic acids: formic, acetic, lactic, glycolic, 2-hydroxybutanoïc, xyloisosaccharinic and glucoisosaccharanic.

The same phases have been observed by Modell et al. in the 1970's after their experiments on forest products [36].

Therefore, the aim of this paper is the understanding of particles formation during hydrothermal conversion since the mechanism is a compromise between physical considerations (creation of spheres) and chemistry (mainly polymerization reaction). The understanding of phenomena involved in solid formation is fundamental to optimize the hydrothermal conversion of raw materials.

For this purpose, the experiments have been performed with black liquor, a wastewater from paper industry. Black liquor is an aqueous alkaline medium containing dissolved lignin, and minerals as well. Using this feedstock, the study will be limited to the secondary char formation. The presence of minerals in the black liquor is also of great interest to investigate their impact on the solid formation. Indeed, minerals are intercalated in the lattice of amorphous carbon during carbonization to create porosity $[37,38]$. In addition, the reactions being performed in batch reactor, we decided to observe the particle generation in the liquid phase, thus subcritical conditions (such as for hydrothermal liquefaction) have been selected. The mechanism of carbon particles formation was investigated at $350{ }^{\circ} \mathrm{C}, 16.5 \mathrm{MPa}$, in a batch reactor, by varying reaction time, heating and cooling rate.

\section{Materials and methods}

\subsection{Reagents}

Black liquor was supplied by a paper company established in Facture, France. It came from the digester after recovery of tall oil in Kraft process. The composition of the raw black liquor is given in Table 1 . Black liquor is an alkaline aqueous media $(\mathrm{pH}=13.2)$ containing $23 \mathrm{wt} . \%$ of dry matter, with a density of $1120 \mathrm{~kg} \mathrm{~m}^{-3}$. The ratio inorganic / organic content is equal to 0.44 ; this ratio means that inorganic and organic represent respectively $30 \mathrm{wt}$ \% and $70 \mathrm{wt}$. \% of the dry matter. The proportion of lignin in the black liquor is $\sim 36 \mathrm{wt}$ \%, being considered as the main part of its organic content. Based on the CHNOS elemental analysis performed in the laboratory, the dry black liquor composition is as follows: C (22.50 wt. \%), H (5.30 wt. \%), N (0.14 wt. \%), O (37.34 wt. \%) and S (2.50 wt. $\%)$. The remaining mass of inorganics (32.22 wt. \%) is mostly due to sodium, as shown by ICP measurements of the raw black liquor (see Table 1). For the experiments, black liquor was diluted to 10 wt. \% in ultrapure water to avoid the formation of large mineral particles that may impact the particle size distribution and to limit concentration heterogeneities due to unstirring. The total organic carbon (TOC) of the dilute solution was thus equal to $(10.7 \pm 0.2)$ $\mathrm{gC} \mathrm{L}^{-1}$ and the total inorganic carbon (TIC) represented $(0.6 \pm 0.1)$ 
$\mathrm{gC} \mathrm{L}^{-1}$. The organic matter contained only $(0.104 \pm 0.003) \mathrm{g} \mathrm{L}^{-1}$ of phenolic compounds and $(0.056 \pm 0.001) \mathrm{g} \mathrm{L}^{-1}$ of formaldehyde. The chemical oxygen demand (COD) of the dilute black liquor was equal to $(20.75 \pm 0.42) \mathrm{gO}_{2} \mathrm{~L}^{-1}$. More details about the black liquor characterization could be found in Boucard PhD Thesis [39].

\subsection{Experimental procedure}

Experiments were performed at $350^{\circ} \mathrm{C}$ in non-monitored batch reactors with an inner volume of $5 \mathrm{~mL}$. The reactor was filled at atmospheric temperature and pressure, with the amount of diluted black liquor required to reach reaction autogenous pressure (16.5 $\mathrm{MPa}$ ). The weight of $10 \mathrm{wt}$. \% black liquor solution introduced in the reactor was of $(3.1624 \pm 0.0005) \mathrm{g}$. Five autoclaves were simultaneously placed in a pre-heated oven (Nabertherm muffle furnace or chromatography oven). These two types of ovens allowed to reach the target temperature at specific heating rate. The Nabertherm L5/11/P320 muffle furnace (N) and the chromatography oven (C) were used, providing a mean estimated heating rate of $20^{\circ} \mathrm{C} \mathrm{min}-1$ and $40{ }^{\circ} \mathrm{C} \mathrm{min}^{-1}$, respectively. The reaction time started when the oven had reached the reaction temperature after introducing autoclaves. Although the temperature in the reactor was not homogenously reaching the targeted temperature at time 0 , the same procedure was applied for all the experiments for comparison. After a certain reaction time, reactor was cooled by quench into frozen water to immediately stop the reaction (rapid cooling) or cooled by ambient air (slow cooling). The cooling time was estimated to 30 min for the slow cooling while quenching was instantaneous ( $\mathrm{t}<1 \mathrm{~min}$ ). After reaction liquid and solid were collected and separated by Büchner filtration.

Twelve different reaction times were investigated: $15 \mathrm{~min}, 30$ min, 45 min, 60 min, 90 min, 2 h, 3 h, 4 h, 6 h, 15 h, 18 h and 24 h. For a sake of clarity selected and significant data are displayed in the figures among the reaction times. For the other reaction times, data are available in the supplementary material.

The name of the samples indicates the heating method ( $\mathrm{N}$ for Nabertherm or C for chromatography oven), the cooling method ( $\mathrm{T}$ for quenching and $\mathrm{L}$ for ambient air cooling) then the reaction time. For example, CT 60 min means that the reaction was performed in chromatography oven $\left(40{ }^{\circ} \mathrm{C} \mathrm{min}-1\right)$ with quenching, and the reaction time was $60 \mathrm{~min}$ at $350^{\circ} \mathrm{C}$.

\subsection{Physical and chemical analyses of liquid and solid phases}

Solid obtained from hydrothermal carbonization was characterized using particles size distribution, elemental analysis, microscopy (transmission electron microscopy and environmental scanning electron microscopy) and Fourier Transform infrared spectroscopy. Particle size distribution was performed with a Mastersizer 3000 Malvern before separation of solid and liquid phases. The size of the analyzed particles could vary from a few nanometers to several millimeters. The elemental analysis was performed using a CHNS/O analyzer (Thermo NA 2100). O content was measured separately from the $\mathrm{C}, \mathrm{H}, \mathrm{N}$ and $\mathrm{S}$ elements. Environmental scanning electron microscopy (ESEM, Philips XL 30 FEG) was used to observe the solids morphology. The samples were observed in ESEM without any preparation. FTIR (PERKIN ELMER 200 FTIR) was used for identifying the presence of functional groups.

Liquid phase was analyzed using several techniques. Total Organic Carbon (TOC) was measured using a Shimadzu COT-meter (COT-5050). The total organic carbon values were deduced from the total carbon and total inorganic carbon measurements. The values of TOC contents in the liquid phase before and after reaction allow assessing the conversion of organic carbon from the initial black liquor. Chemical oxygen demand (COD) was measured using

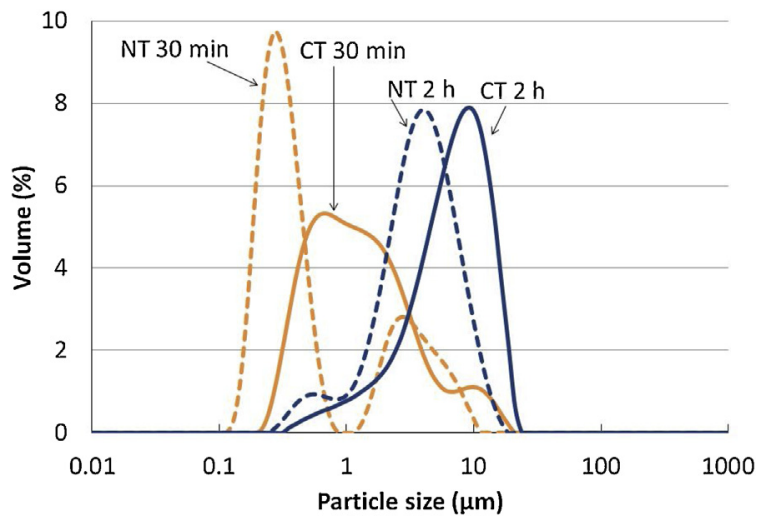

Fig. 1. Influence of heating rate $\left(\mathrm{NT} 20^{\circ} \mathrm{C} \mathrm{min}^{-1}\right.$ and $\mathrm{CT} 40^{\circ} \mathrm{C} \mathrm{min}-1$ ) on the particle size distribution at $350{ }^{\circ} \mathrm{C}, 16.5 \mathrm{MPa}, 30 \mathrm{~min}$ and $2 \mathrm{~h}$ after quenching: NT $30 \mathrm{~min}$ (dashed orange line), CT 30 min (solid orange line), NT 2 h (dashed blue line), and CT 2 h (solid blue line).

test cuvettes from Hach Lange. COD indicates the mass of oxygen $\left(\mathrm{O}_{2}\right)$ consumed per liter of solution. It is expressed in $\mathrm{mg} \mathrm{L}^{-1}$ or $\mathrm{ppm}$. This parameter gives information on the oxidation degree of molecules in the aqueous media. Indeed, COD measures the amount of $\mathrm{O}_{2}$ required to achieve oxidation. This analysis was carried out under acid conditions in a solution with sulfuric acid and potassium dichromate with test cuvette (LCK014, LCK514). After reaction, the sample was analyzed at the wavelength of $605 \mathrm{~nm}$ for ranges (100-2000) $\mathrm{mg} \mathrm{L}^{-1}$ (LCK514) and (1000-10000) $\mathrm{mg} \mathrm{L}^{-1}$ (LCK014). Total phenols and formaldehyde were also measured using test cuvettes from Hach Lange: LCK346 (510 nm) and LCK325 $(412 \mathrm{~nm})$ respectively.

\section{Results}

The experimental results reported in our study were obtained in 5 similar reactors operated together under the same conditions.

\subsection{Influence of heating and cooling rate}

Hydrothermal conversion of black liquor was performed at $350{ }^{\circ} \mathrm{C}$ using two different heating rates: $\approx 20{ }^{\circ} \mathrm{C} \mathrm{min}^{-1}$ with Nabertherm oven, namely $\mathrm{N}$, and a faster heating rate of $\approx 40{ }^{\circ} \mathrm{C}$ $\min ^{-1}$ with chromatography oven, namely C. After the reaction time ( $30 \mathrm{~min}$ or $2 \mathrm{~h}$ ), the reactors were quenched (T label) to atmospheric temperature. Fig. 1 shows the particle size distribution of the recovered solids after $30 \mathrm{~min}$ and $2 \mathrm{~h}$ of reaction time using a low heating rate (NT) and a faster heating rate (CT). The particle size distribution corresponds to two populations particles (two Gaussian peaks) at low heating rate and short reaction time (NT $30 \mathrm{~min}$ ), while the faster heating rate results in a larger size distribution (CT $30 \mathrm{~min}$ ). At slow heating rate, the size of the particles was comprised between $0.1 \mu \mathrm{m}$ and $1 \mu \mathrm{m}$ for the first population and (1-18) $\mu \mathrm{m}$ for the second population. With faster heating the particle size distribution was broader and showed the overlapping of three main different populations of particles with mode diameters of each population of $0.8 \mu \mathrm{m}, 2.1 \mu \mathrm{m}$ and $12.7 \mu \mathrm{m}$. ESEM pictures acquired on both solids are presented in Fig. 2 . These images confirmed the large heterogeneity in size distribution of particles from fast heating rate (Fig. 2(a)) and after 30 min reaction time. By increasing the reaction time to $2 \mathrm{~h}$, the particle size distribution was determined after quenching. Fig. 1 shows that both profiles (CT 2 h and NT 2 h) are quite similar showing a Gaussian peak with a shoulder at low particle sizes. The mode diameter of the particles from fast heating rate (CT $2 \mathrm{~h}$ ) was higher (about $10 \mu \mathrm{m}$ ) than at lower heating rate (about 

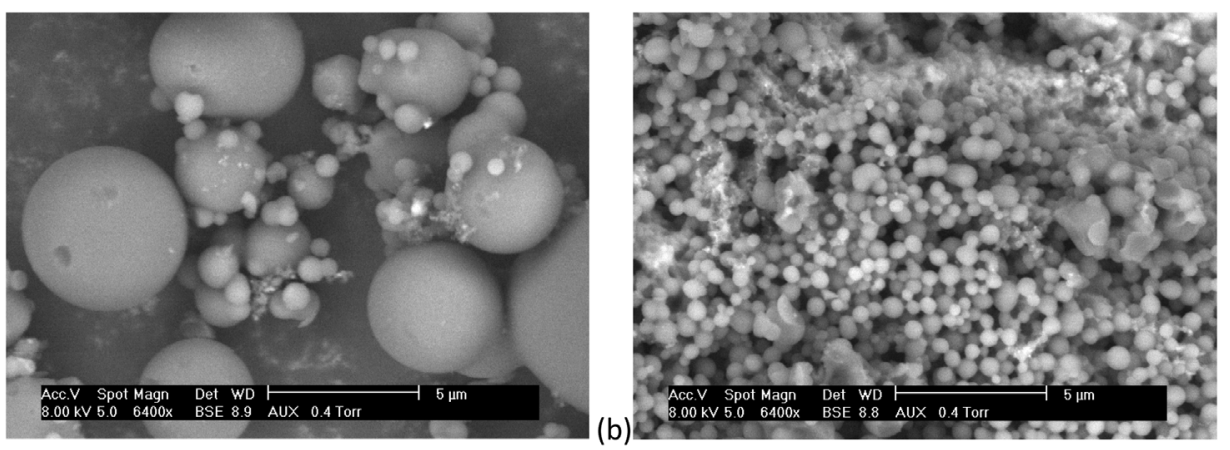

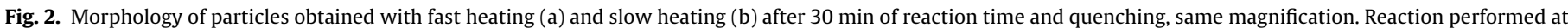
$350{ }^{\circ} \mathrm{C}$ and $16.5 \mathrm{MPa}$.



Fig. 3. Particle size distributions of solids recovered after 60 min reaction time ( 350 ${ }^{\circ} \mathrm{C}$ and $16.5 \mathrm{MPa}$ ) after ambient air cooling (CL $60 \mathrm{~min}$, dashed line) and quenching (CT $60 \mathrm{~min}$, solid line).

$5 \mu \mathrm{m})$. The heating rate impacted to a lesser extent the morphology of the particles at longer reaction time.

The cooling rate impact was also investigated in this study. Using the same reactor (fast heating rate, $40{ }^{\circ} \mathrm{C} \mathrm{min}^{-1}$ ), the particle size distribution was measured after $60 \mathrm{~min}$ reaction time and quenching (CT, about $1 \mathrm{~min}$ ) or slow cooling (CL, about $30 \mathrm{~min}$ ). Fig. 3 shows that the particle size distributions have almost the same profiles, shifted to higher diameters for slow cooling (CL). Since quenching is operated to approach the morphology of the particles at the reaction temperature, the particle size distribution tends to show a coalescence phenomenon during the cooling phase.

\subsection{Influence of reaction time}

To investigate the influence of the reaction time, experiments were performed with fast heating and quenching to recover particles with morphology as close as possible to that in the reaction medium. Although an oily phase appeared during the reaction and its proportion increased with reaction time, the volume was too low to be quantified.

\subsubsection{Morphology of the recovered solid}

Recovered solids after quenching were analyzed by ESEM, and their corresponding images are presented in Fig. 4 (and Figure S1, supplementary material). The particle size distributions are also shown in Fig. 5 (and Figure S2, supplementary material).

Fig. 4 shows that spherical particles are observed at $30 \mathrm{~min}$ of reaction time. The size of the particles slightly increased at $60 \mathrm{~min}$. Then at $90 \mathrm{~min}$ and $4 \mathrm{~h}$, the solid was composed of aggregates. At $90 \mathrm{~min}$ (Fig. 4) and $2 \mathrm{~h}$ reaction time (Figure S1) the spherical particles could be seen as entrapped in the aggregate. At $3 \mathrm{~h}$ (Figure S1) and 4 h reaction time (Fig. 4), the spherical particles were not easily identified even with increased enlargement. After 6 h (Fig- ure S1), the spherical particles were sometimes distinguished at the smooth surface of the aggregates. For $15 \mathrm{~h}$ reaction time (Fig. 4), the spherical particles were easily observed and seemed to be embedded in a fine plastic phase that had been solidified. Finally, after $24 \mathrm{~h}$ reaction time, very small spherical particles were observed as isolated particles or in the aggregates (Fig. 4).

Fig. 5 shows the particle size distributions obtained from the laser granulometry at some reaction times. The overall particle size distributions are displayed in Figure S2 (supplementary material). As observed using ESEM, most of the particles were spherical for selected reaction time, meaning that calculated diameters almost fitted with geometric diameters. For the aggregates, which were not spherical, the particle size would give an equivalent diameter of the aggregates. Comparing data acquired with microscope and laser granulometry, it could be seen that particles sizes of about $(0.4$ to 0.5$) \mu \mathrm{m}$ were resulting from spherical particles while equivalent diameters of more than $3 \mu \mathrm{m}$ were showing aggregates features. It could be observed that the isolated spherical particles should likely be observed at reaction times of $30 \mathrm{~min}, 60 \mathrm{~min}$ and $24 \mathrm{~h}$. These observations agree with the ESEM images (Fig. 4 and Figure S1). The particle size distribution shows an increase in mode diameter with reaction time: $4.58 \mu \mathrm{m}$ (90 $\mathrm{min}$ ); $8.68 \mu \mathrm{m}$ (120 min), $21.2 \mu \mathrm{m}$ ( $3 \mathrm{~h}$ and $4 \mathrm{~h}$ ). The increase in the size of the aggregates was likely due to coalescence up to $3 \mathrm{~h}$ reaction time. At $4 \mathrm{~h}$ and $6 \mathrm{~h}$ reaction time, the particle size distributions gave the same mode diameter of $21.2 \mu \mathrm{m}$. At $15 \mathrm{~h}$ reaction time, the particle size distribution and the ESEM images showed that the solid was formed of aggregates. At $15 \mathrm{~h}$ or $18 \mathrm{~h}$, the mode diameter of the aggregates was increased to $52 \mu \mathrm{m}$ and $67 \mu \mathrm{m}$ respectively. This increase was likely due to a coalescence, indicating that the solidification of the external transition layer should mainly occur during cooling and not at subcritical conditions. However, ESEM pictures indicated that the aggregates were formed with spherical particles for these reaction times (15 $\mathrm{h}$ and $18 \mathrm{~h}$ ). The volume of small particles was thus slightly higher at $15 \mathrm{~h}$ reaction time compared to $4 \mathrm{~h}$.

The size of the particles increased with the reaction time that was mostly due to the particle growth or agglomeration. Figs. 1 and 2 also showed that the size of the spherical particles was larger at fast heating rate. The heating rate had a great impact on the activation of the reactions that were involved. In other words, dissolved lignin was modified with reaction temperature due to hydrolysis, decarboxylation or degradation reactions. At a faster heating rate, the mechanism was going straighter to degradation reaction increasing thus the amount of smaller molecules in the media. The highest size of the particles at higher reaction time seemed to be linked with higher concentration of degradation products around a nucleus. This hypothesis could be confirmed since at longer reaction time the shift of the particle size distribution between slow and fast heating was less significant than after 30 min reaction time. In addition, after $30 \mathrm{~min}$ reaction, the quenching 

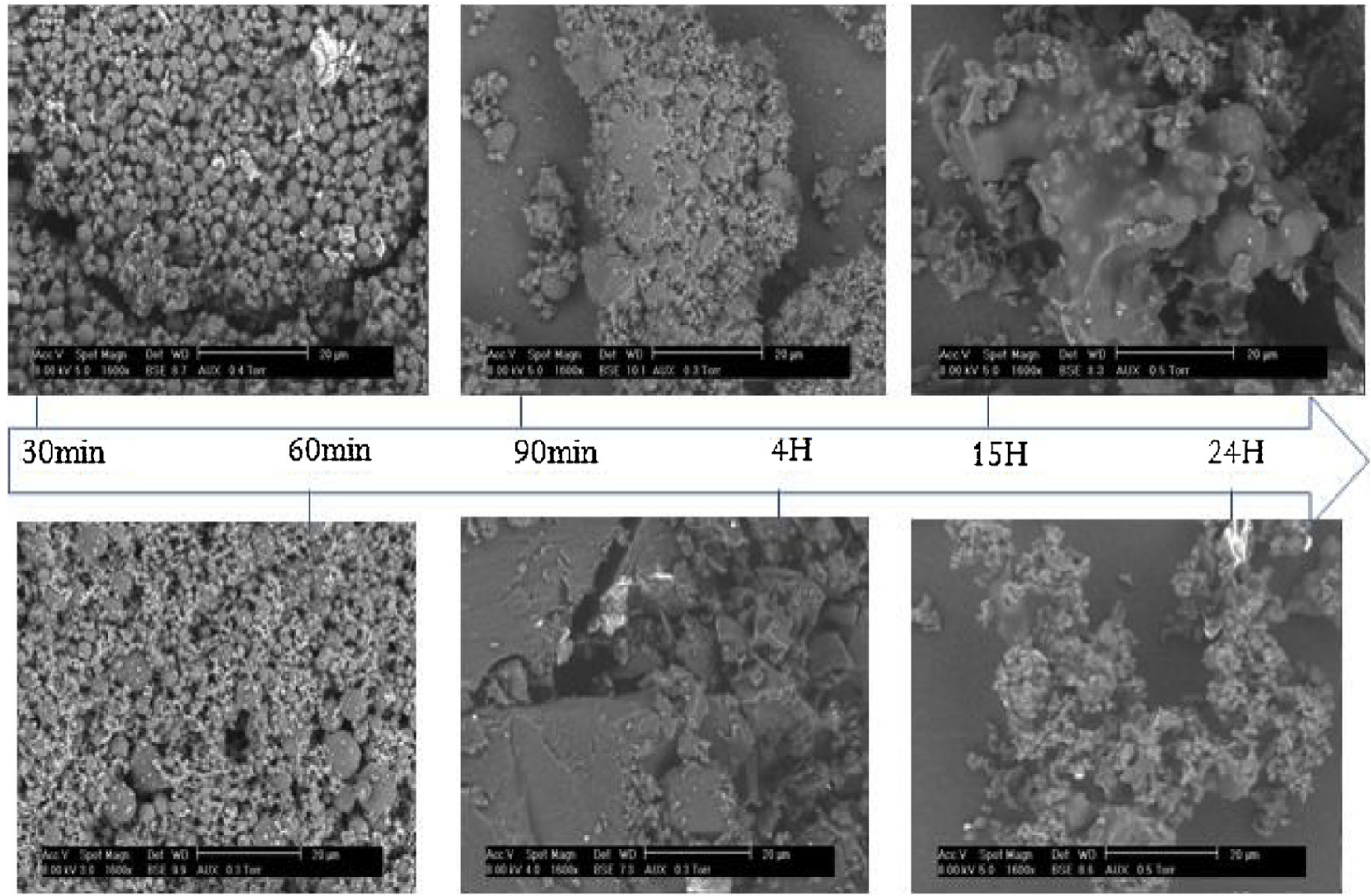

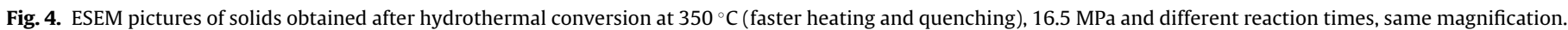

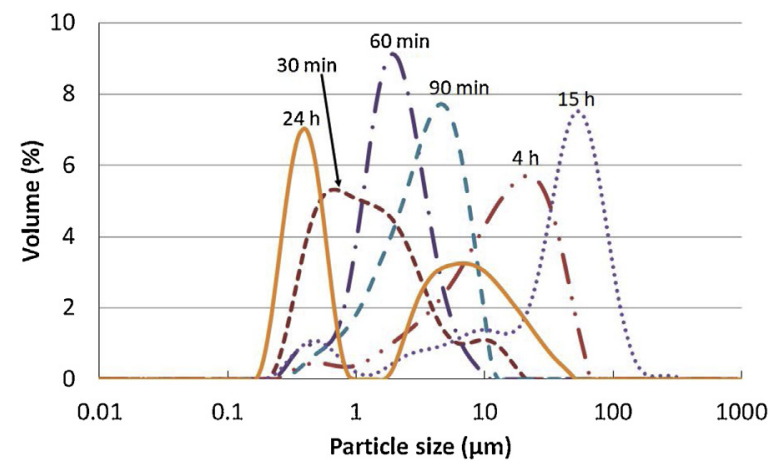

Fig. 5. Particle size distributions of the solids obtained after hydrothermal conversion at $350{ }^{\circ} \mathrm{C}, 16.5 \mathrm{MPa}$ (faster heating rate and quenching) for various reaction times: CT $30 \mathrm{~min}$, CT $60 \mathrm{~min}$, CT $90 \mathrm{~min}$, CT $4 \mathrm{~h}$, CT $15 \mathrm{~h}$ and CT $24 \mathrm{~h}$.

resulted in smaller diameters of the spherical particles compared to ambiant air cooling. When performing a quenching, the objective was to immobilize the media as such. In other words, diffusion, coalescence and other phenomena that were resulting in a larger reactive zone were avoided. Therefore it is expected that the solid formation should result from a small stabilized area, such as for example an emulsion.

\subsubsection{Chemical composition of the recovered solid}

Elemental analysis of the solids was also performed. Fig. 6 shows the carbon, oxygen and hydrogen molar composition over reaction time. The values of molar composition at 0 min correspond to the black liquor solution introduced in the reactor. $\mathrm{C}$ and $\mathrm{O}$ contents quickly evolved from the liquid black liquor composition to the solid composition during the first 30 min of reaction time. This composition slowly evolved after $30 \mathrm{~min}$ and then tended to be stabilized (for sake of clarity, data between $3 \mathrm{~h}$ and $24 \mathrm{~h}$ are not included in the graph). Although the morphology changed with

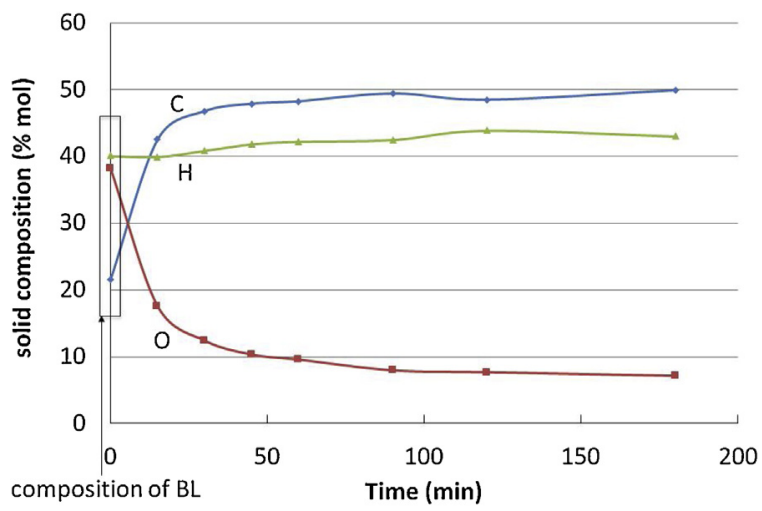

Fig. 6. Elemental analysis ( $\mathrm{C}, \mathrm{O}$ and $\mathrm{H}$ ) of solids over reaction time (faster heating rate and quenching).

the reaction time, the chemical composition was not significantly modified and corresponds to about $\mathrm{C}_{5} \mathrm{H}_{4} \mathrm{O}$ as chemical formula.

FTIR analysis was performed with all the carbonaceous solids. All the spectrums were similar to the one presented in Fig. 7. The peaks observed close to $3000 \mathrm{~cm}^{-1}$ correspond to $\mathrm{CH}$ stretching (in $-\mathrm{CH}_{3}$ and $-\mathrm{CH}_{2}-$ ) of saturated (under) and unsaturated molecules (above). The peaks around $1600 \mathrm{~cm}^{-1}$ and $1450 \mathrm{~cm}^{-1}$ correspond to the $\mathrm{C}=\mathrm{C}$ bonds of the aromatic rings. The large peak around $3300 \mathrm{~cm}^{-1}$ corresponds to the free $-\mathrm{OH}$ function and/or $-\mathrm{OH}$ intermolecular bonds (hydrogen bonding).

The combination of these peaks revealed the presence of alcohol function and aromatic rings which derived from phenolic compounds obtained by cleavage of the lignin; and their repolymerization. The profile obtained is in agreement with other hydrochars from biomass [40]. The other peaks were not precisely identified, and the one at $1350 \mathrm{~cm}^{-1}$ may correspond to a double bond $\mathrm{S}=\mathrm{O}$. This is in agreement with microanalysis performed with EDS detector that highlighted the presence of sulfur. The broad peak at $1250 \mathrm{~cm}^{-1}$ may correspond to the vibration of the CO bond of 




Fig. 7. FTIR spectrum of solid residue obtained after reaction (faster heating rate and quenching).

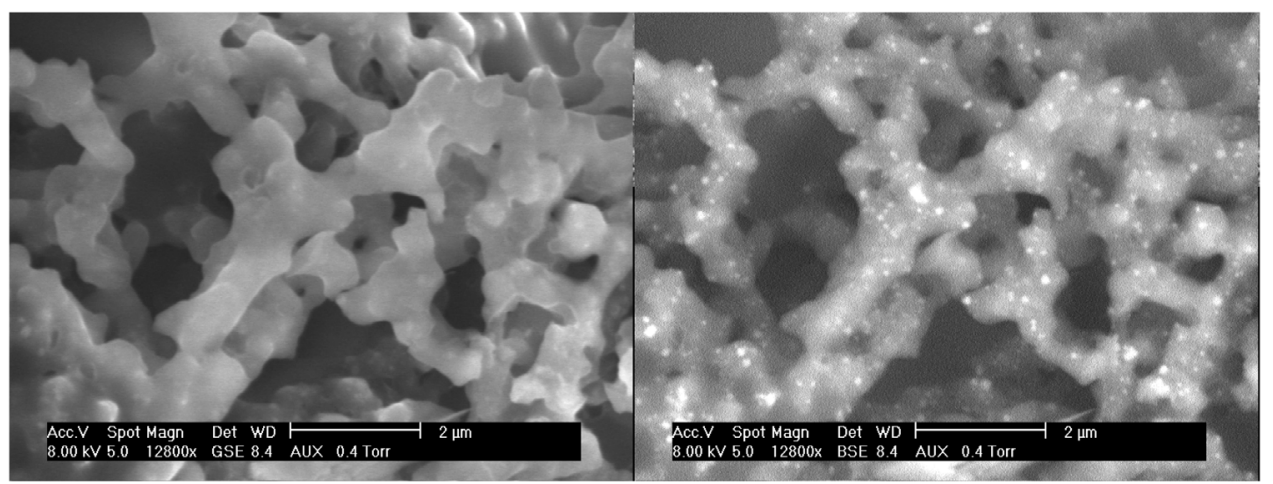

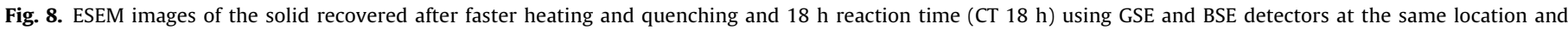
magnification (x12800).

acetate. FTIR analysis suggested hydrophilic surface of the obtained carbonaceous solid. The literature confirms that hydrothermal carbonization is known to produce carbonaceous microparticles with a hydrophilic shell [41]. However, compared to Sevilla et al., the $\mathrm{O} / \mathrm{C}$ atomic ratio of the obtained solid is significantly lower than that obtained by the authors [42]. Thus, the hydrophilic character is less important.

At the operating conditions $\left(350{ }^{\circ} \mathrm{C}, 16.5 \mathrm{MPa}\right)$, the salts are prone to precipitate, and their participation cannot be excluded as a carrier of the solid formation, as shown by Rahmani et al. [43]. Indeed, ICP analyses performed on liquid phase showed that 10 wt. \% of minerals were removed from the liquid phase and therefore were recovered in the solid phase. Salts have been detected in the carbonaceous solid phase using ESEM and EDX detector during microscopy analyses. Fig. 8 shows ESEM pictures acquired at the same location with Ground Secondary Electrons (GSE) and BackScattering Electrons (BSE) detectors. This solid, recovered after 18 $\mathrm{h}$ reaction time, highlights that minerals were mainly included in the carbonaceous matrix (BSE detector) rather than covering the surface (GSE detector). In addition, the mineral inclusions were very small compared to the size of the particles meaning that salts could act as a carrier for carbonaceous solid formation. Microanalysis also showed that sodium $(\mathrm{Na})$ was included in solid particles, while sulfur was mainly found at the surface at short reaction time (see Fig. 9). Mochida et al. [44] studied sulfur behavior during hydrothermal carbonization and showed that desulfurization of organic matter occurred firstly forming organic sulfur compounds in liquid phase or sulfured salts which precipitated.

\subsubsection{Liquid analysis}

After reaction, the color of the aqueous phase was changing from dark black (initial solution) to transparent brown at $45 \mathrm{~min}$ then orange at $90 \mathrm{~min}$, yellow after $4 \mathrm{~h}$ and close to clear water at $15 \mathrm{~h}$ (colors of the solutions are shown in the supplementary material, Figure S3). The color change was due to the presence of lower molecules such as aromatic compounds and oligosaccharides that are chromophore. Chemical Oxygen Demand (COD) and Total Organic Carbon (TOC) as well were measured in the aqueous phase. 

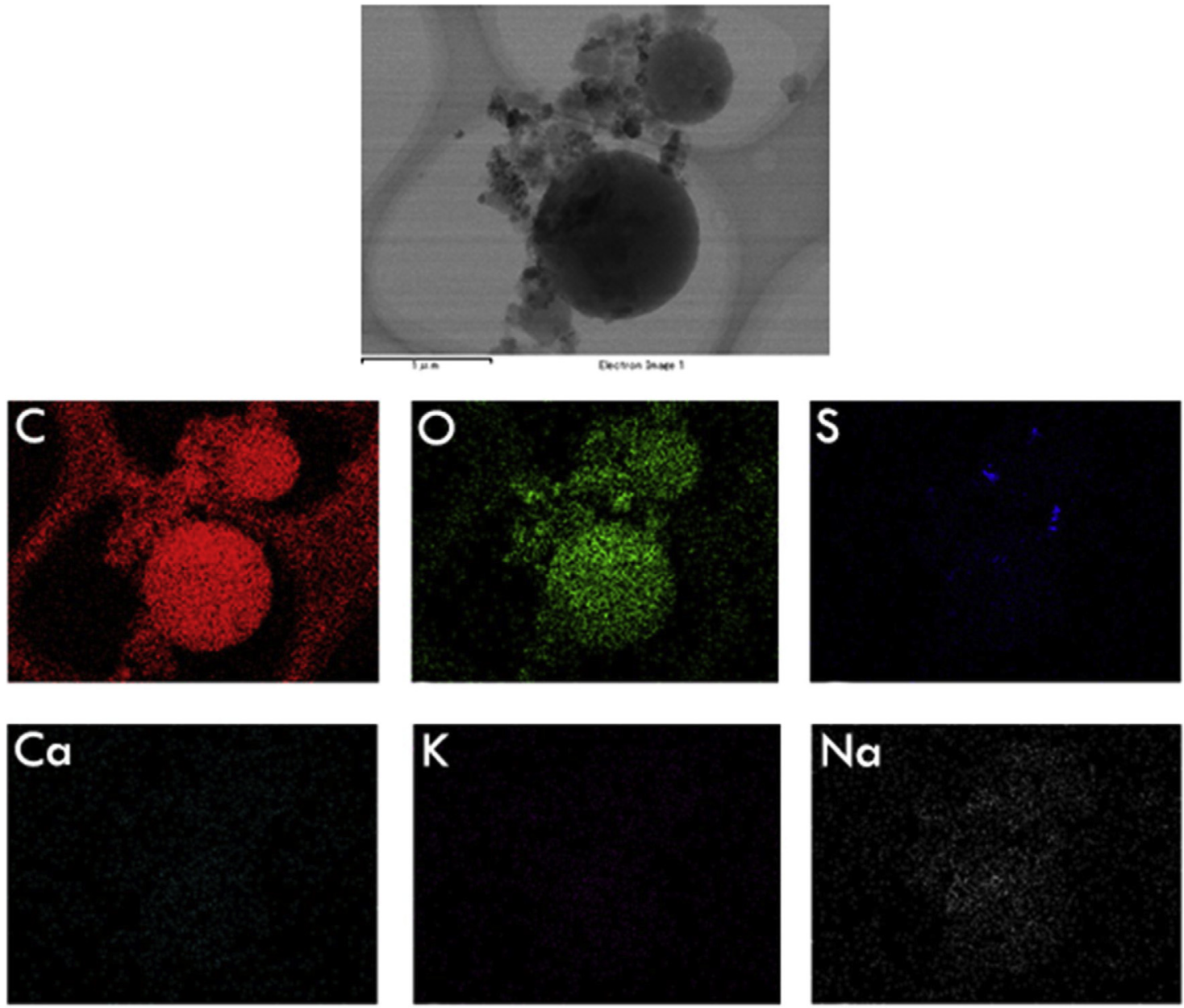

Fig. 9. TEM observation and EDX mapping of particles obtained after fast heating (C) and quenching (T) for $1 \mathrm{~h}$ reaction time.

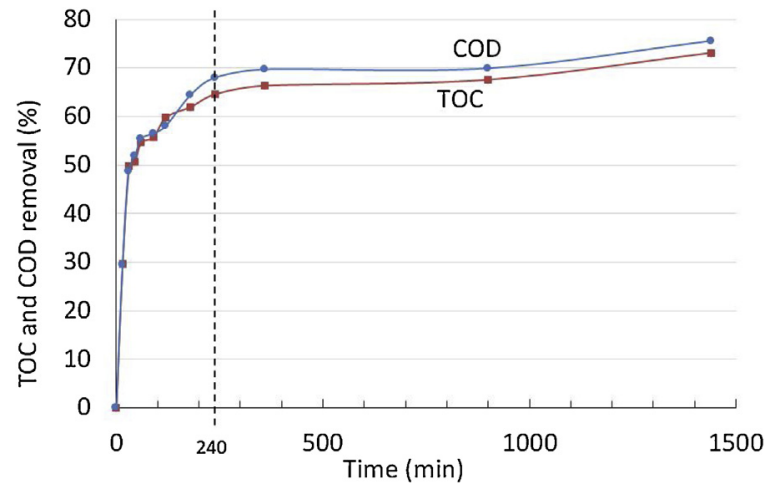

Fig. 10. Chemical Oxygen Demand (COD, blue line and circle symbols) and Total Organic Carbon (TOC, red line and square symbols) removal of solution over reaction time (faster heating rate and quenching, reaction at $350^{\circ} \mathrm{C}$ and $16.5 \mathrm{MPa}$ ).

Fig. 10 shows that TOC and COD removals are quickly increasing to almost $50 \%$ in $30 \mathrm{~min}$, then the increase is moderate until 4 $\mathrm{h}$ and the removals are almost stabilized to $15 \mathrm{~h}$ followed by a slight increase to $24 \mathrm{~h}$ reaction time. This quick increase in COD and TOC removals agrees with the color of the solution, meaning that the chemical reactions involved in the liquid phase were dominant until 30 min reaction time, and to a lesser extent until $4 \mathrm{~h}$. Surprisingly the TOC and COD removals were almost equal at 60 and $90 \mathrm{~min}$. TOC and COD removals follow the same trends meaning that the oxidation and mineralization rates were equal in the aque-



Fig. 11. Total phenols (red line with square symbols) and formaldehyde (blue line and circle symbols) concentrations over reaction time (faster heating rate and quenching, reaction at $350^{\circ} \mathrm{C}$ and $16.5 \mathrm{MPa}$ ).

ous media. Above $4 \mathrm{~h}$ reaction time, the oxidation rate was slightly higher than the mineralization rate. This could be explained by the reactions involved in the liquid media or due to the formation of the solid phase.

The brown, orange, yellow colors of the solutions are often related to phenols and their relative oligomers. In addition, polymerization reactions are induced by the simultaneous presence of phenols and aldehydes in a liquid media. Phenols and formaldehyde concentrations were also measured in the liquid phase (Fig. 11). A significant increase in phenols concentration was observed during 



Reaction time

$90 \min <$

Reaction time

$<4$ h

Reaction time

$>4 \mathrm{~h}$

Aromatization $\rightarrow>$ release of small molecules $->$ porosity
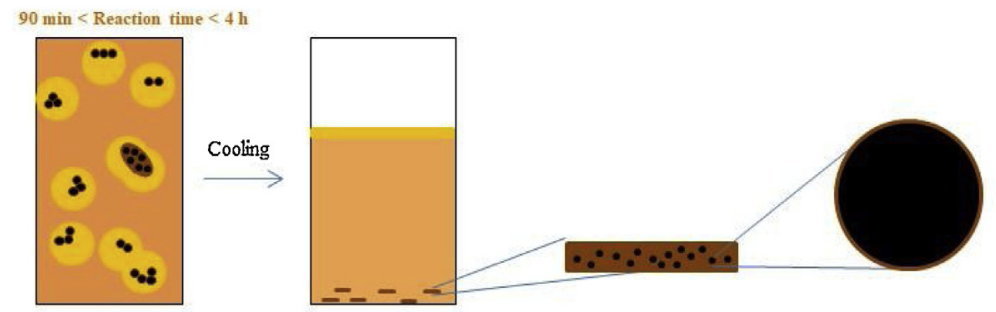

Coalescence of oily phase $->$ coalescence of transition layer $\rightarrow>$ carbon spherule trapped


Aromatization of carbon $\rightarrow$ growth of new particles by radius axis $\rightarrow>$ carbon spherule emerged

Fig. 12. Suggested mechanism of particle formation during hydrothermal conversion of black liquor at $350{ }^{\circ} \mathrm{C}, 16.5 \mathrm{MPa}$, and the corresponding morphology observed at atmospheric conditions.

the first 15 min of reaction time confirming that dissolved lignin molecules were fragmented to smaller ones. The concentrations significantly evolved up to $4 \mathrm{~h}$ reaction time, and then tended to be stabilized.

The composition of the solid phase quickly evolved increasing the carbon content and decreasing the oxygen content (compared to the original dried black liquor). The solid formed was thus far from the dissolved lignin that composed the black liquor. The composition of the liquid phase showed a severe decrease of the COD and TOC in the aqueous media. Obviously, the carbon content, and organics content, decreased significantly due to the degradation reaction, the oil production and the formation of solid. It is well-known that the char formation follows a two-step process as primary (solid-solid reactions) and secondary char formation [45]. Secondary char formation considers a liquid-solid conversion, from the raw material to "base unit molecules" then to solid, thus the decomposition of lignin into phenolic compounds and aldehydes, as intermediate base units, forms phenols-aldehyde base units, and thus the carbonaceous material. From 90 min reaction time, the composition of the solid phase did not change significantly. Thus, the change in particle/aggregate size could not mainly due to chemical reactions. From 90 min to 4 h reaction time, TOC and COD removals in the aqueous phase still increased but to a lesser extent. In this range of reaction time the concentration of aldehydes was almost stabilized.

\section{Discussion}

From solid and liquid analyses, a suggested mechanism is presented in Fig. 12, to explain the morphology of the solid formed from black liquor at $350^{\circ} \mathrm{C}$, with faster heating rate and quenching.

From the literature, some authors, such as La Mer [34] or Titirici et al. [27,46], explained that firstly carbon microspheres were formed, then they grew and coalesce to form a continuous media. The particles obtained for short reaction time in our experiments were similar to those obtained by Titirici (Fig. 12, $\mathrm{t}<90 \mathrm{~min}$ ). Decomposition of black liquor created, inter alia, phenols and aldehydes which polymerized together and form an intermediate base 


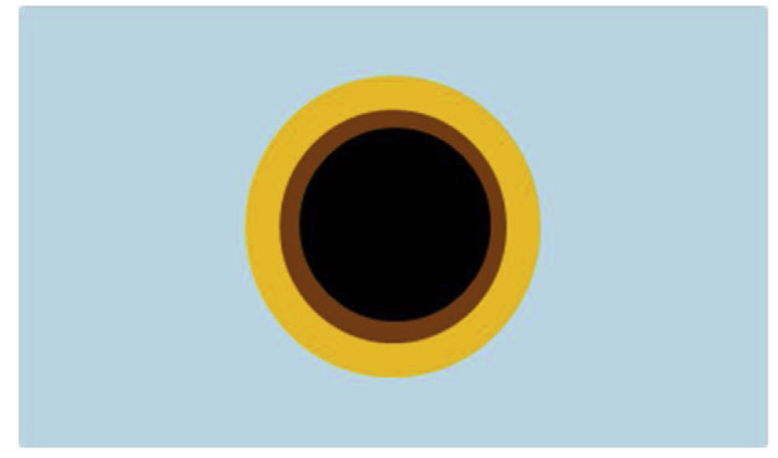

Fig. 13. Scheme of the organic droplet organization in the subcritical water. The yellow circle represents the oily droplet, the brown circle the transition layer and the black circle the carbonaceous particles.

unit. As mentioned previously an oily phase was also observed after cooling down the reactor. At atmospheric temperature and pressure this oily phase was clearly separated from the aqueous media. At the subcritical conditions, due to a decrease in the water density, the densities of both phases were found out to be close, and an oil-in-water emulsion was expected to be stable. Thus a bio-oil film from hydrothermal liquefaction was formed and was concentrated in oxygenated organic reactive compounds such as hydroxy aldehyde, hydroxyketones, carboxylic acid and polyphenolic compounds [11]. This film was then encapsulating droplets containing high concentrations of "intermediate base units". In the droplets, the supersaturation of phenols and aldehydes resulted in a nucleation of the oligomers, followed by a maturation. As seen in Fig. 1, the size of the particles was increased using a fast heating rate. With a shorter heating time, the reactions were quickly oriented to the phenols production and the supersaturation occurred probably to a larger extent. During this step, the transition media (also called transition layer or transition phase) was located at the interface of carbon spherules (Fig. 13), and acted as a reservoir for the solid formation. Fig. 13 shows the yellow circle for the oily droplet, the brown circle for the transition layer and the black circle for the carbonaceous particle. The amount of transition phase was balanced between its production from the organic phase and its consumption to the carbon spherules. Therefore, a radial gradient of phenolsaldehyde intermediate concentration existed from the surface of oily phase to the carbon spherule. As far as coalescence is observed, several particles could be generated within a same oily droplet. After cooling, the oily phase was separated from the aqueous phase, the remaining thin transition layer was dissolved in the aqueous phase and the spherical carbonaceous particles were recovered and dispersed in the liquid media (Fig. 12). As seen in Fig. 3, quenching resulted in smaller particles than slow cooling. This indicated that the size of the droplets was smaller at subcritical conditions and the coalescence continued during the slow cooling.

At $90 \mathrm{~min}$, coalescence began due to Brownian movement (Fig. 14), resulting in the formation of aggregates. For reaction time between $2 \mathrm{~h}$ and $3 \mathrm{~h}$, the coalescence continued while it was limited between 3 and $4 \mathrm{~h}$ since both solids showed the same particle size distribution (Fig. 12, $90 \mathrm{~min}<\mathrm{t}<4 \mathrm{~h}$ ). The amount of transition layer likely increased up to $3 \mathrm{~h}$, since TOC and COD removal increased. The oily droplets, and the transition layer as well, coalesced in the media at subcritical conditions. However, after $3 \mathrm{~h}$ reaction time the coalescence was limited, due to the weight of the aggregates or due to a partial solidification of the transition layer (Fig. 14). The second hypothesis is of particular interest since it can explain that the carbon spherules were not clearly seen on the aggregates but likely entrapped in the blocks of aggregates. In addition, the phenols concentration showed a peak at $2 \mathrm{~h}$ reaction time, when measured at atmospheric conditions. One of the hypotheses would be a demixing of the emulsion that released a certain amount of "transition layer" to be dissolved in the aqueous media at atmospheric conditions. This means that a greater amount of the transition layer was likely not solidified at subcritical conditions after $2 \mathrm{~h}$ reaction time compared to $90 \mathrm{~min}$ or $3 \mathrm{~h}$.

After $4 \mathrm{~h}$ reaction time (Fig. 12, t $>4 \mathrm{~h}$ ), the compositions of the liquid and the solid phases were not significantly modified. Therefore, the modifications in solid morphology were rather due to physical phenomena than chemical reactions. The morphology of the solid was significantly changed from $4 \mathrm{~h}$ to $18 \mathrm{~h}$ reaction time. It has been explained that the spherical particles were not observed in the solid at $4 \mathrm{~h}$ reaction time. By increasing the reaction time, the layer seemed to be thinner and the spherical particles were observed at the surface of aggregates. However, the diameter of the spherical particle observed was clearly lower than the spherules obtained at $60 \mathrm{~min}$. This could indicate that the spherules were newly formed and did not correspond to the original ones.

Some authors, such as Inagaki or Ayache et al. [29,31,47], considered that carbonaceous particles were formed in a continuous media due to a local change in aromaticity. A mesophase appeared, containing small spherules [48]. As the spherules grew, the coalescence of mesophase spherules resulted in the formation of a continuous mesophase matrix. Furthermore, the spheres or agglomerated spheres of carbonaceous particles suggested that this material was liquid or plastic at operating conditions [43]. These latter suggestions could explain that the coalescence was limited between $4 \mathrm{~h}$ and $6 \mathrm{~h}$ due to a high viscosity of the plastic mesophase. By increasing the reaction time, the aromaticity was locally chang-

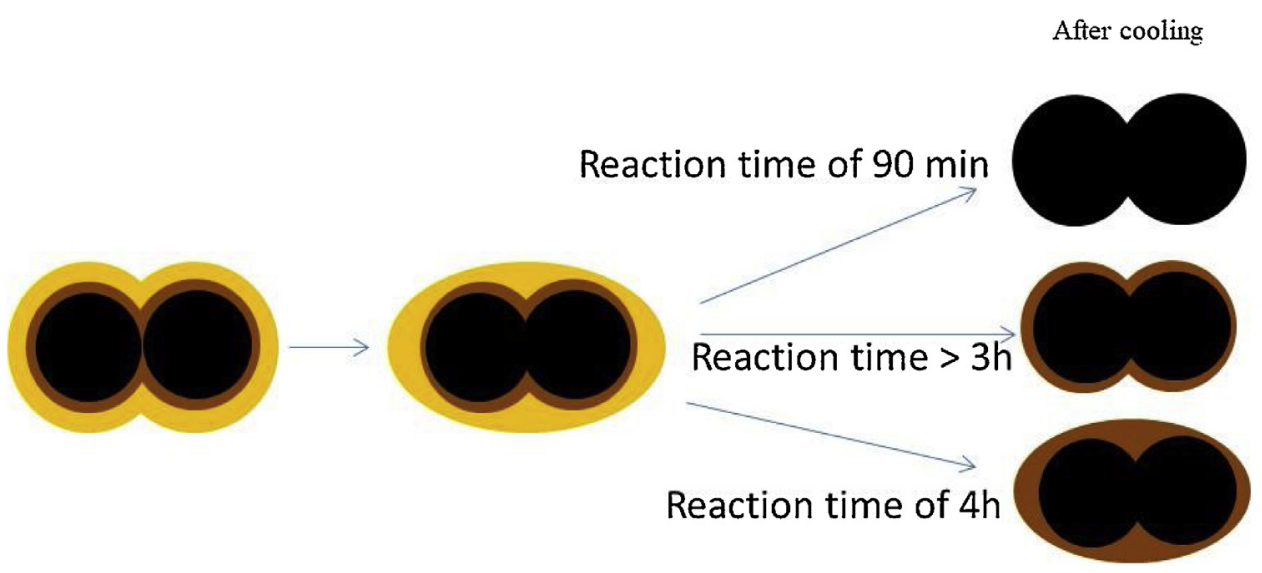

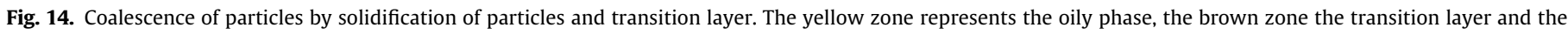
black zone the carbonaceous particles. 
ing creating some small spherules. The continuous emergence of carbon spherules tended to decrease the viscosity of the mesophase resulting in the observation of the spheres embedded in a very thin phase.

\section{Conclusions}

As explained in the previous section, the solid formation at short reaction time agrees well with the theory developed by La Mer or Titirici $[27,34]$. Firstly, carbon microspheres were formed in the transition layer due to a supersaturation of smaller molecules from the black liquor decomposition (mainly reactions between phenols and aldehydes). Then the spherical carbon material grew due to maturation and coalescence phenomena. After a certain reaction time (90 $\mathrm{min}$ ) the spherical carbon particles were rather observed in aggregates than as isolated particles. Between $3 \mathrm{~h}$ and $6 \mathrm{~h}$ reaction time the coalescence of aggregates was limited since the mode diameter was almost stable. For longer reaction time, the solid observed showed aggregates where the spherical particles of small diameter were visible. These microspheres observed in a continuous media likely corresponded to a second theory developed by Shimokawa et al. or Ayache et al. [22,47]. They considered that carbonaceous particles were formed in a continuous media, namely mesophase, due to a local change in aromaticity. This formation was rather due to local physical rearrangement than chemical reactions. Both mechanisms seem to explain the evolution of solid morphology in our experiments. In fact, chemical and physical mechanisms involved in the hydrothermal conversion of the black liquor solution coexist and operate with different kinetics all along the reaction time. Thus the solid morphology does not match with only one theory. It has been proposed that the oily phase encapsulates the transition layer or the mesophase to create an isolated droplet where the transition layer progressively turned into a plastic mesophase with higher viscosity.

The experiments performed in this study are quite far from the literature devoted to hydrothermal carbonization since the starting material was dissolved in the liquid phase. The degradation of the black liquor resulted in the formation of a bio-oil that was not mentioned by the other authors working with saccharides dissolved in the aqueous media [42]. It has been also observed that the shell of the carbon sphere would be less hydrophilic than that mentioned in the literature $[18,42]$ due to a lower overall $\mathrm{O} / \mathrm{C}$ atomic ratio. Thus, the presence of the oily/organic phase around the carbon particle as an emulsion is possible.

\section{Acknowledgements}

The authors want to thank Christine Rolland and Philippe Accart for their assistance in analyzing the solids. This manuscript is based on the Ph.D. Thesis of Hélène Boucard from the University of Toulouse defended in 2014.

\section{References}

[1] P.E. Savage, S.G. Gopalan, T.I. Mizan, C.J. Martino, E.E. Brock, Reactions at supercritical conditions: applications and fundamentals, AIChE 41 (1995) 1723-1778, http://dx.doi.org/10.1002/aic.690410712.

[2] A. Kruse, E. Dinjus, Hot compressed water as reaction medium and reactant. Properties and synthesis reactions, J. Supercrit. Fluids 39 (2007) 362-380, http://dx.doi.org/10.1016/j.supflu.2006.03.016.
[3] M.D. Bermejo, M.J. Cocero, Supercritical water oxidation: a technical review, AIChE 52 (2006) 3933-3951, http://dx.doi.org/10.1002/aic.10993.

[4] Z. Fang, T. Sato, R.L. Smith, H. Inomata, K. Arai, J.A. Kozinski, Reaction chemistry and phase behavior of lignin in high-temperature and supercritical water, Bioresour. Technol. 99 (2008) 3424-3430, http://dx.doi.org/10.1016/j. biortech.2007.08.008.

[5] R.L. Smith, P. Atmaji, Y. Hakuta, M. Kawaguchi, T. Adschiri, K. Arai, Recovery of metals from simulated high-level liquid waste with hydrothermal crystallization, J. Supercrit. Fluids 11 (1997) 103-114, http://dx.doi.org/10. 1016/S0896-8446(97)00030-2.

[6] M.T. Munir, S.S. Mansouri, I.A. Udugama, S. Baroutian, K.V. Gernaey, B.R. Young, Resource recovery from organic solid waste using hydrothermal processing: opportunities and challenges, Renew. Sust. Energy Rev. 96 (2018) 64-75, http://dx.doi.org/10.1016/j.rser.2018.07.039.

[7] S.R.A. Kersten, B. Potic, W. Prins, W.P.M. Van Swaaij, Gasification of model compounds and wood in hot compressed water, Ind. Eng. Chem. Res. (2006), http://dx.doi.org/10.1021/ie0509490.

[8] C. Xu, J. Lancaster, Conversion of secondary pulp/paper sludge powder to liquid oil products for energy recovery by direct liquefaction in hot-compressed water, Water Res. 42 (2008) 1571-1582, http://dx.doi.org/ 10.1016/j.watres.2007.11.007.

[9] K. Tekin, S. Karagöz, S. Bektaş, A review of hydrothermal biomass processing, Renew. Sust. Energy Rev. 40 (2014) 673-687, http://dx.doi.org/10.1016/j.rser. 2014.07.216.

[10] M. Déniel, G. Haarlemmer, A. Roubaud, E. Weiss-Hortala, J. Fages, Energy valorisation of food processing residues and model compounds by hydrothermal liquefaction, Renew. Sust. Energy Rev. 54 (2016) 1632-1652, http://dx.doi.org/10.1016/j.rser.2015.10.017.

[11] A.R.K. Gollakota, N. Kishore, S. Gu, A review on hydrothermal liquefaction of biomass, Renew. Sust. Energy Rev. 81 (2018) 1378-1392, http://dx.doi.org/10. 1016/j.rser.2017.05.178.

[12] K. Byrappa, S. Ohara, T. Adschiri, Nanoparticles synthesis using supercritical fluid technology - towards biomedical applications, Adv. Drug Deliv. Rev. 60 (2008) 299-327, http://dx.doi.org/10.1016/j.addr.2007.09.001.

[13] A. Sahraneshin, S. Takami, D. Hojo, K. Minami, T. Arita, T. Adschiri, Synthesis of shape-controlled and organic-hybridized hafnium oxide nanoparticles under sub- and supercritical hydrothermal conditions, J. Supercrit. Fluids 62 (2012) 190-196, http://dx.doi.org/10.1016/j.supflu.2011.10.019.

[14] M.-M. Titirici, R.J. White, C. Falco, M. Sevilla, Black perspectives for a green future: hydrothermal carbons for environment protection and energy storage, Energy Environ. Sci. 5 (2012) 6796, http://dx.doi.org/10.1039/C2EE21166A.

[15] M.-M. Titirici, M. Antonietti, Chemistry and materials options of sustainable carbon materials made by hydrothermal carbonization, Chem. Soc. Rev. 39 (2010) 103-116, http://dx.doi.org/10.1039/B819318P.

[16] B. Hu, K. Wang, L. Wu, S.-H. Yu, M. Antonietti, M.-M. Titirici, Engineering carbon materials from the hydrothermal carbonization process of biomass, Adv. Mater. 22 (2010) 813-828, /doi/epdf/10.1002/adma.200902812.

[17] D. Basso, F. Patuzzi, D. Castello, M. Baratieri, E.C. Rada, E. Weiss-Hortala, L. Fiori, Agro-industrial waste to solid biofuel through hydrothermal carbonization, Waste Manage. 47 (Part A) (2016) 114-121, http://dx.doi.org/ 10.1016/j.wasman.2015.05.013.

[18] T. Wang, Y. Zhai, Y. Zhu, C. Li, G. Zeng, A review of the hydrothermal carbonization of biomass waste for hydrochar formation: process conditions, fundamentals, and physicochemical properties, Renew. Sust. Energy Rev. 90 (2018) 223-247, http://dx.doi.org/10.1016/j.rser.2018.03.071.

[19] M. Kumar, A.O. Oyedun, A. Kumar, A review on the current status of various hydrothermal technologies on biomass feedstock, Renew. Sust. Energy Rev. 81 (2018) 1742-1770, http://dx.doi.org/10.1016/j.rser.2017.05.270.

[20] X.Z. Zhuang, H. Zhan, Y.Q. Huang, Y.P. Song, X.L. Yin, C.Z. Wu, Conversion of industrial biowastes to clean solid fuels via hydrothermal carbonization (HTC): Upgrading mechanism in relation to coalification process and combustion behavior, Bioresour. Technol. 267 (2018) 17-29, http://dx.doi. org/10.1016/j.biortech.2018.07.002.

[21] E. Dinjus, A. Kruse, N. Tröger, Hydrothermal carbonization - 1. influence of lignin in lignocelluloses, Chem. Eng. Technol. 34 (2011) 2037-2043, http://dx. doi.org/10.1002/ceat.201100487.

[22] S. Shimokawa, E. Yamada, T. Yokono, J. Yamada, Y Sanada, M. Inagaki, High temperature high pressure ${ }^{1} \mathrm{H}-\mathrm{NMR}$ study on formation of carbon spherules, Carbon 24 (1986) 771-772, https://doi-org/10.1016/0008-6223(86)90187-9.

[23] S. Kang, X. Li, J. Fan, J. Chang, Solid fuel production by hydrothermal carbonization of black liquor, Bioresour. Technol. 110 (2012) 715-718, http:/ dx.doi.org/10.1016/j.biortech.2012.01.093.

[24] H. Boucard, M. Watanabe, S. Takami, E. Weiss-Hortala, R. Barna, T. Adschiri, Beneficial use of $\mathrm{CeO}_{2}$ nanocatalyst for black liquor conversion under sub and supercritical conditions, J. Supercrit. Fluids 105 (2015) 66-76, http://dx.doi. org/10.1016/j.supflu.2015.02.008.

[25] K. Okuda, M. Umetsu, S. Takami, T. Adschiri, Disassembly of lignin and chemical recovery-rapid depolymerization of lignin without char formation in water-phenol mixtures, Fuel Process. Technol. 85 (2004) 803-813, http:// dx.doi.org/10.1016/j.fuproc.2003.11.027.

[26] P.L. Walker, Carbon: an old but new material revisited, Carbon 28 (1990) 261-279, http://dx.doi.org/10.1016/0008-6223(90)90001-F.

[27] M.-M. Titirici, Hydrothermal Carbonisation: A Sustainable Alternative to Versatile Carbon Materials, 2012 http://opus.kobv.de/ubp/volltexte/2013/ $6688 /$. 
[28] J.D. Brooks, G.H. Taylor, The formation of graphitizing carbons from the liquid phase, Carbon 3 (1965) 187-193, http://dx.doi.org/10.1016/00086223(65)90047-3.

[29] J. Ayache, A. Oberlin, M. Inagaki, Mechanism of carbonization under pressure Part II: influence of impurities, Carbon 28 (1990) 353-362, http://dx.doi.org/ 10.1016/0008-6223(90)90008-M.

[30] M. Inagaki, Carbon materials- structure, texture and intercalation, Solid State Ion. 88 (1996) 833-839, http://dx.doi.org/10.1016/0167-2738(96)00337-2.

[31] M. Inagaki, K.C. Park, M. Endo, Carbonization under pressure, New Carbon Mater 25 (2010) 409-420, http://dx.doi.org/10.1016/S1872-5805(09)600421.

[32] M. Inagaki, Discussion of the formation of nanometric texture in spherical carbon bodies, Carbon (1997) 711-713, https://doi-org/10.1016/S0008-6223(97)86645-6.

[33] K. Azami, S. Yamamoto, Y. Sanada, Kinetics of mesophase formation of petroleum pitch, Carbon 32 (1994) 947-951, http://dx.doi.org/10.1016/00086223(94)90054-X.

[34] V.K. La Mer, Nucleation in phase transitions, Ind. Eng. Chem. 44 (1952) 1270-1277, http://dx.doi.org/10.1021/ie50510a027.

[35] Z. Fang, R.L. Smith, J.A. Kozinski, T. Minowa, K. Arai, Reaction of d-glucose in water at high temperatures $\left(410^{\circ} \mathrm{C}\right)$ and pressures $(180 \mathrm{MPa})$ for the production of dyes and nano-particles, J. Supercrit. Fluids 56 (2011) 41-47, http://dx.doi.org/10.1016/j.supflu.2010.11.009.

[36] M. Modell, R.P. Overend, T.A. Milne, L.K. Mudge, Gasification and Liquefaction of Forest Products in Supercritical Water in: Fundamentals of Thermochemical Biomass Conversion, 1985, pp. 95-120, http://dx.doi.org/10. 1007/978-94-009-4932-4_6.

[37] L. Khezami, A. Chetouani, B. Taouk, R. Capart, Production and characterisation of activated carbon from wood components in powder: cellulose, lignin, xylan, Powder Technol. 157 (2005) 48-56, http://dx.doi.org/10.1016/j.powtec. 2005.05.009.

[38] V. Fierro, V. Torné-Fernández, A. Celzard, Highly microporous carbons prepared by activation of Kraft lignin with $\mathrm{KOH}$, Stud. Surf. Sci. Catal. 160 (2006) 607-614, http://dx.doi.org/10.1016/S0167-2991(07)80078-4.
[39] H. Boucard, Contributions to the Understanding of Hydrothermal Processes: Application to Black Liquor. PhD Thesis From the University of Toulouse, 2014 https://tel.archives-ouvertes.fr/tel-01178183/file/BOUCARD_Helene_2014 Diff.pdf.

[40] Z. Liu, A. Quek, S. Kent Hoekman, R. Balasubramanian, Production of solid biochar fuel from waste biomass by hydrothermal carbonization, Fuel 103 (2013) 943-949, http://dx.doi.org/10.1016/j.fuel.2012.07.069.

[41] R. Demir-Cakan, N. Baccile, M. Antonietti, M.-M. Titirici, Carboxylate-rich carbonaceous materials via one-step hydrothermal carbonization of glucose in the presence of acrylic acid, Chem. Mater. 21 (2009) 484-490, http://dx.doi. org/10.1021/cm802141h.

[42] M. Sevilla, A.B. Fuertes, Chemical and structural properties of carbonaceous products obtained by hydrothermal carbonization of saccharides, Chemistry 15 (2009) 4195-4203, http://dx.doi.org/10.1002/chem.200802097.

[43] S. Rahmani, W. McCaffrey, J.A.W. Elliott, M.R. Gray, Liquid-phase behavior during the cracking of asphaltenes, Ind. Eng. Chem. Res. 42 (2003) 4101-4108, http://dx.doi.org/10.1021/ie020921d.

[44] I. Mocida, T. Ando, K. Maeda, H. Fujitsu, K. Takeshita, Catalytic carbonization of aromatic hydrocarbons - IX: Carbonization mechanism of heterocyclic sulfur compounds leading to the anisotropic coke, Carbon 18 (1980) 131-136, http://dx.doi.org/10.1016/0008-6223(80)90021-4.

[45] S. Kang, X. Li, J. Fan, J. Chang, Hydrothermal conversion of lignin: a review, Renew. Sust. Energy Rev. 27 (2013) 546-558, http://dx.doi.org/10.1016/j.rser. 2013.07.013.

[46] M.-M. Titirici, M. Antonietti, N. Baccile, Hydrothermal carbon from biomass- a comparison of the local structure from poly- to monosaccharides and pentoses/hexoses, Green Chem. 10 (2008) 1204-1212, http://dx.doi.org/10. 1039/B807009A.

[47] J. Ayache, A. Oberlin, M. Inagaki, Mechanism of carbonization under pressure. part I: influence of aromaticity, Carbon 28 (1990) 337-351, http://dx.doi.org/ 10.1016/0008-6223(90)90007-L.

[48] Y.A. Lebedev, A.P. Krekhov, A.N. Chuvyrov, N.K. Gil'manova, Disclination structures of carbonaceous mesophase spherules, Carbon 24 (1986) 719-724, https://doi-org/10.1016/0008-6223(86)90180-6. 